\title{
Mechanistic Investigations of an $\alpha$-Aminoarylation Photoredox Reaction
}

\author{
Bernard G. Stevenson, Ethan H. Spielvogel, Emily A. Loiaconi, Victor Wambua, Roman V. Na- \\ khamiyayev, John R. Swierk ${ }^{*}$ \\ Department of Chemistry, State University of New York at Binghamton, Vestal, NY 13850
}

\begin{abstract}
Photoredox methods continue to transform modern synthetic chemistry yet there is a lack of detailed mechanistic information about these reactions. Using a combination of steady state photochemical measurements, transient laser spectroscopy, and electrochemical methods we rigorously characterize an $\alpha$-aminoarylation mechanism that is the inspiration for a large number of photoredox reactions. While the overall product yield is high, the external quantum yield of the reaction is independent of light intensity only $15 \%$ to $30 \%$ depending on the length of the reaction. The reaction rate is also independent of light intensity when normalized to the number of incident photons. By assigning rate constants to the key productive and unproductive pathways, this allows us to identify and rationalize the rate-limiting step: deprotonation of an N-phenylpyrrolidine radical cation. Finally, we develop a simple kinetic model that allows us to predict how changing different kinetic parameters can impact the quantum yield of the reaction.
\end{abstract}

\section{INTRODUCTION.}

By utilizing visible light to drive challenging synthetic transformations, photoredox catalysis is profoundly changing modern synthetic chemistry. In the twelve years since the first simultaneous reports from MacMillan ${ }^{1}$ and Yoon, ${ }^{2}$ the number and scope of photoredox reactions has exploded. ${ }^{3-7}$ While photoredox methods have developed at a remarkable pace, a detailed mechanistic understanding has lagged behind. Most reports typically offer a degree of mechanistic insight through some combination of Stern-Volmer measurements, redox potentials of the reaction components, bond dissociation energies, and variation in reagent concentration. ${ }^{8-11}$ While this can give information about the initial steps in the reaction, subsequent steps are less well characterized. A detailed mechanistic understanding involves direct knowledge of each intermediate as well as the kinetics of the productive and unproductive steps. This information can then be used to improve the reaction yields or reaction completion times. $^{12,13}$

Despite a wide variation in the details, all photoredox methods utilize a photocatalyst to absorb light and initiate the reaction. This photocatalyst is often a transition metal complex with long-lived excited states, though there are many examples using metal-free, organic photocatalysts. ${ }^{8,14,15}$ Once a photon is absorbed, the excited state of the photocatalyst can function as either a potent oxidant or reductant, which allows the photocatalyst to generate high energy intermediates that otherwise cannot be achieved by other thermal type reactions. ${ }^{16}$ Typically, photoredox reactions proceed via single electron transfer (SET) to a target substrate, which then generates a radical species that subsequently undergoes a bond-forming coupling reaction. Importantly, visible light allows reactions to occur without the use of harsh reaction conditions or reagents that are classically used in synthetic transformations. $^{17}$

Mechanistic information on photoredox reactions rarely includes rate constants or direct observation of intermediates after the initial steps in the reaction. Nocera and coworkers used a combination of spectroscopic, electrochemical, and computational methods to fully characterize the catalytic cycle and rate constants of a hydroamidation photoredox reaction and with that information were able to address low quantum yields. $^{12}$ In a related example, Orr-Ewing and coworkers were able to determine the rate constants for electron transfer (ET) and radical prop- 
agation steps for an atom transfer radical polymerization using transient IR techniques. ${ }^{18,19}$ Several other groups have utilized transient absorption spectroscopy to observe reaction intermediates in photoredox reactions. ${ }^{20-28}$

$\alpha$-arylamines and substituted nitrogen heterocycles are important structural motifs in medicinal chemistry. ${ }^{29}$ Generation of these motifs using latent $\mathrm{sp}^{3} \mathrm{C}-\mathrm{H}$ bonds via cross-coupling of amines and aryl building blocks has attracted significant attention, ${ }^{30,31}$ with photoredox reactions representing a particularly attractive approach. ${ }^{32}$ The pioneering report on the photoredox generation of $\alpha$-arylamines was first reported by MacMillan and coworkers, ${ }^{33}$ though the use of cyanoarenes and $\alpha$-amine radicals was subsequently generalized for a host of other photoredox transformations $^{34-42}$ and more recently to electrosynthetic chemistry. ${ }^{43}$ All of these reactions build on the mechanism first proposed by MacMillan ${ }^{33}$ using the prototype coupling of 1,4dicyanobenzene (DCB) and N-phenylpyrrolidine (NPP) to generate 4-(1-phenyl-2pyrrolidinyl)benzonitrile (Scheme 1). On the basis of Stern-Volmer emission quenching studies and redox potentials, they propose that upon excitation of an iridium photocatalyst an electron is transferred to DCB to generate a radical anion and $\operatorname{Ir}(\mathrm{IV})$ species. The $\operatorname{Ir}(\mathrm{IV})$ species subsequently oxidizes NPP to generate the NPP ${ }^{*+}$ radical cation and regenerate the ground state catalyst. In their mechanistic proposal, this NPP radical cation is then deprotonated by sodium acetate to give the NPP ${ }^{\circ}$ radical, which couples with the $\mathrm{DCB}^{--}$radical anion to form the target product.

Scheme 1. Prototype $\alpha$-aminoarylation reaction from MacMillan and coworkers. ${ }^{33}$

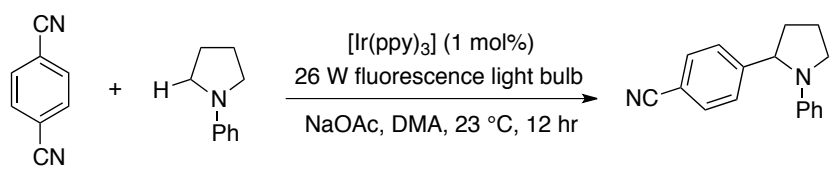

Despite the importance $\alpha$-arylamines and related photoredox reactions, the reaction mechanism and kinetics are poorly characterized. Recently, Walker et al. ${ }^{44}$ examined the coupling of DCB and 2-methyl-1-phenylpiperidine. In that work they determined the rate constant for back electron transfer between $\mathrm{DCB}^{\cdot-}$ and $\left[\operatorname{Ir}(\mathrm{ppy})_{3}\right]^{+}$, as well as the rate constant for the oxidation of the piperidine by $\left[\operatorname{Ir}(\mathrm{ppy})_{3}\right]^{+}$, but the rest of the reaction mechanism was left unexplored. In this work, we utilize a combination of reaction quantum yield measurements, transient absorption spectroscopy (TAS), and electrochemistry to characterize productive and unproductive pathways in the catalytic coupling of DCB and NPP and assign rate constants to all steps. From this we are able to identify and rationalize the ratelimiting step in the catalytic cycle. Finally, using the rate constants obtained from TAS experiments, we develop a kinetic model that is in good agreement with experimental measurements and allows us to predict the effect of changing different reaction parameters.

\section{METHODS.}

Fac-tris(2-phenylpyridine C,N)iridium (III) $\left(\operatorname{Ir}(\mathrm{ppy})_{3}\right), \mathrm{N}, \mathrm{N}$-dimethylactemide (DMA), and 1,4-dicyanobenzene (DCB) were purchased from Sigma Aldrich and used as received. Nphenylpyrrolidine (NPP) was purchased from Alfa Aesar and used as received.

Quantum Yield Measurements. DCB and sodium acetate were crushed with a mortar and pestle and the sodium acetate was dried at $100{ }^{\circ} \mathrm{C}$ in a drying oven prior to use. A stirring flea was placed into a screwtop $1 \mathrm{~cm}$ pathlength cuvette along with $\operatorname{Ir}(\text { ppy })_{3}(2.5 \mu \mathrm{mol}, .005$ equiv $)$, DCB (0.5 mmol, 1 equiv), and sodium acetate (1.0 mmol, 2 equiv), followed by 30 minutes of purging with argon. Degassed DMA $(2 \mathrm{~mL})$ and NPP (1.5 mmol, 3 equiv) were added via a syringe. The solution was then bubbled through with argon gas for an additional 45 minutes. For reactions that varied in light intensity, the cuvette was placed on a stirring plate with a $3 \mathrm{D}$ printed cuvette holder in front of a collimated $415 \mathrm{~nm}$ LED (Thor Labs M15LP1) for 1-30 hours. The LED power was measured using a calibrated photodiode (Thor Labs S120C). For wavelengthdependent reactions, the cuvette was placed on a stir plate in front of a $950 \mathrm{~W}$ Xe arclamp (Oriel 66921) equipped with a monochromator (Spectral Products CM110) for 2 hours. After illumination, $0.25 \mathrm{mmol}$ of triphenylmethane was added as an internal standard and the reaction allowed to stir for 30 minutes in the dark. $100-200 \mu \mathrm{L}$ of reac- 
tion mixture was then dissolved in $d$-acetonitrile and the reaction yield calculated with quantitative ${ }^{1} \mathrm{H}$ Nuclear Magnetic Resonance.

Stern-Volmer Kinetics. Stern-Volmer kinetics were characterized using solutions of $54 \mu \mathrm{M}$ $\operatorname{Ir}(\mathrm{ppy})_{3}$ in DMA with varying concentrations of DCB. Samples were placed in a four-sided screw top cuvette with septum and purged under argon for 90 minutes. Emission data from 450-750 nm was collected using Shimadzu RF-6000 Spectro Fluorophotometer using an excitation wavelength of $425 \mathrm{~nm}$.

\section{Transient Absorption Spectroscopy (TAS)} Experimentation. Transient absorption experiments were carried out using a Spectra-Physics Quanta-Ray Pro-290 pulsed Nd:YAG laser (10 $\mathrm{Hz}$ ) fitted with a PrimoScan OPO. An excitation wavelength of $415 \mathrm{~nm}\left(900 \mu \mathrm{J} / \mathrm{cm}^{2}\right)$ was used for all experiments. Laser pulses were chopped at every other pulse to improve the signal to noise ratio per the method of Rimshaw, et. al. ${ }^{45}$ The sample was illuminated with a broadband white light source (Energetiq EQ-99X), with a shutter before the sample to minimize light exposure. After the sample, probe light was collected by a monochromator (Spectral Products DK240) and passed onto a silicon photodiode (ThorLabs DET10A). Data was collected with a Pico Technology 6404C oscilloscope and analyzed using software written in LabView.

Single wavelength traces were collected at $6.4 \mathrm{~ns}$ intervals up to $12 \mu \mathrm{s}$ and at $1 \mu \mathrm{s}$ intervals up to $10 \mathrm{~ms}$. The short-time and long-time data traces were stitched together before fitting. For short-time traces, data was collected with the probe on and off to remove any residual laser scattering. For TAS experiments, solution concentrations of $37 \mu \mathrm{M} \operatorname{Ir}(\mathrm{ppy})_{3}, 50 \mathrm{mM} \mathrm{DCB}$, and $150 \mathrm{mM}$ NPP in DMA were used. Solutions were prepared under an argon atmosphere for 90 minutes in a four-sided screw top cuvette with cap and septum before TAS experiments. Samples were changed every two hours with stability confirmed by comparing single wavelength traces at the same wavelength collected at different times throughout the experiment. The TAS traces were fit to a kinetic model described in the supporting information.
Spectrochemical Studies. All spectroelectrochemical experiments were performed using a BioLogic SP-50 potentiostat, a platinum honeycomb spectroelectrochemical cell (Pine) with a pathlength of $1.7 \mathrm{~mm}$, and a Shimadzu UV-2600 $\mathrm{UV}-\mathrm{Vis}$ Spectrophotometer. Electrochemical potentials were applied relative to a $\mathrm{Ag} / \mathrm{Ag}^{+}$reference electrode. For all spectroelectrochemical studies, $0.1 \mathrm{M}$ tetrabutylammonium hexafluorophosphate $\left(\mathrm{TBAPF}_{6}\right)$ in DMA was used as the electrolyte. Concentrations of 83 and $590 \mu \mathrm{M}$ were used for $\operatorname{Ir}(\mathrm{ppy})_{3}$ and $\mathrm{DCB}$, respectively. Spectroelectrochemical studies of NPP failed to produce a stable spectrum for the radical cation and were not pursued.

\section{RESULTS AND DISCUSSION}

Quantum yield measurements. Typically, photoredox reactions fall into one of two categories: radical chain mechanisms or non-radical chain mechanisms. A radical chain mechanism involves an initial formation of a radical species via the closed photoredox cycle, which then interacts with another neutral species to form subsequent radicals in a chain propagation step. These mechanisms reflect a quantum yield greater than one as a single photoredox cycle can yield multiple reactive radicals via chain propagation, which can translate to multiple products formed per absorbed photon. Non-radical chain mechanisms on the other hand correspond to formation of a single product molecule with each photoredox cycle. Ideally, the internal quantum yield is one, indicating that every absorbed photon results in product formation. In practice, most quantum yields are less than one because of deactivation steps.

We characterized the time dependent quantum yields (QY) and product yields at 10.4 $\mathrm{mW} \mathrm{cm}{ }^{-2}$ (Figure 1) and $5.06 \mathrm{~mW} \mathrm{~cm}^{-2}$ (Figure S1) and observed a maximum product yield of $86 \%$. Though the overall reaction rate was slower at lower illumination intensities, the photon normalized reaction rates were $2.75 \mathrm{mmol} \mathrm{hr}^{-1} \mathrm{~W}^{-1}$ for $10.4 \mathrm{~mW} \mathrm{~cm}^{-2}$ and $2.76 \mathrm{mmol} \mathrm{hr}^{-1} \mathrm{~W}^{-1}$ for $5.06 \mathrm{~mW} \mathrm{~cm}^{-2}$, which suggests that light intensity did not affect quantum yield in this intensity range. 


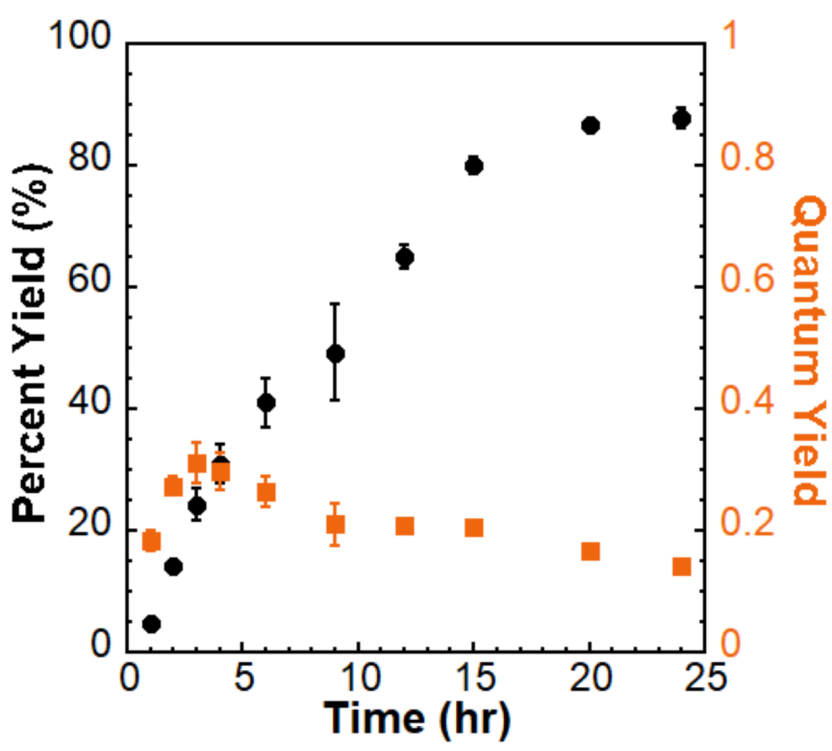

Figure 1. Percent yield (black circles) and external quantum yield (orange squares) of reaction illuminated by a $415 \mathrm{~nm}$ LED. $\left(10.4 \mathrm{~mW} \mathrm{~cm}^{-2}\right)$

At an excitation wavelength of $415 \mathrm{~nm}$, we observed QY in the range of 0.15-0.3, (Figure 1) depending on the length of the reaction, which is consistent with the $\alpha$-arylation reaction not proceeding through a radical chain pathway. At long reaction times, we observe a decrease in the quantum yield, which can be explained by a decrease in the concentrations of DCB and NPP. Interestingly, at short times we see a peak in the quantum yield around three hours (Figure 1). We propose this is related to sodium acetate acting as a proton scavenger and the generation of acetic acid (vide infra). Follow up studies to understand this mechanistic nuance are planned.

A reaction quantum yield of $0.15-0.3$ is in good agreement with other studies on non-radical chain propagation reactions, where typical quantum yields of photoredox reactions can range from 0.19 to $0.43 .^{46-48}$ Ellman and coworkers partly explored the mechanism of a closely related $\alpha$-amino arylation reaction involving substituted piperidine analogues and observed 0.4-0.6 at early timescales, ${ }^{44}$ which is in relatively good agreement with our quantum yields. These results were collected without the use of insoluble sodium acetate, which may explain the higher quantum yield.

We also explored the quantum yield as a function of wavelength (Figure S2). In $\operatorname{Ir}(p p y)_{3}$, the main absorption band in the visible and nearUV corresponds to the ${ }^{1}$ MLCT $\left(\mathrm{d}-\pi^{*}\right)$ transition with a max absorption at $\lambda=376 \mathrm{~nm} .{ }^{49}$ The data demonstrates that quantum yield is independent of wavelength, as there was no significant variation in quantum yield until outside the absorption range of $\operatorname{Ir}(\mathrm{ppy})_{3}$.

Electron transfer between DCB and $\operatorname{Ir}(p p y)_{3}$. Two possible pathways exist in the quenching of the excited photocatalyst. The first proceeds via an $\operatorname{Ir}(\mathrm{III}) / \operatorname{Ir}(\mathrm{II})$ cycle where the excited $\operatorname{Ir}(\mathrm{ppy})_{3}$ first oxidizes NPP to generate an NPP radical cation and $\left[\operatorname{Ir}(\mathrm{ppy})_{3}\right]^{-}$then transfers an electron to DCB. Alternatively, the reaction can go through an $\operatorname{Ir}(\mathrm{III}) / \operatorname{Ir}(\mathrm{IV})$ oxidative quenching pathway where DCB initially oxidizes the excited state photocatalyst to generate $\operatorname{Ir}(\mathrm{IV})$. McNally et al. suggest the $\operatorname{Ir}(\mathrm{III}) / \mathrm{Ir}(\mathrm{IV})$ pathway on the basis of the Stern-Volmer analysis of DCB and NPP with $\operatorname{Ir}(\text { ppy })_{3} \cdot{ }^{33}$ Our measurements of the quenching rate, $\mathrm{k}_{\text {quench }}$, of excited $\operatorname{Ir}(\mathrm{ppy})_{3}$ by DCB is $2.2 \mathrm{x}$ $10^{9} \mathrm{M}^{-1} \mathrm{~s}^{-1}$ on the basis of an excited state lifetime of $1.83 \mu \mathrm{s}$, which we determined via transient emission spectroscopy. This corresponds well with the values for $\mathrm{k}_{\text {quench }}$ determined by McNally et. al. ${ }^{33}$ and Walker et al. ${ }^{44}$ of $2.3 \times 10^{9} \mathrm{M}^{-1} \mathrm{~s}^{-1}$ and $2.9 \times 10^{9} \mathrm{M}^{-1} \mathrm{~s}^{-1}$, respectively. By contrast, we did not observe quenching of the excited $\operatorname{Ir}(\mathrm{ppy})_{3}$ when using NPP as the quencher, which again is in good agreement with McNally and coworkers. ${ }^{33}$ We also do not observe any changes in the TAS when exciting $\operatorname{Ir}(\mathrm{ppy})_{3}$ in the presence of NPP. This confirms that the reaction does not proceed via an $\operatorname{Ir}(\mathrm{III}) / \mathrm{Ir}(\mathrm{II})$ cycle but through an $\operatorname{Ir}(\mathrm{III}) / \mathrm{Ir}(\mathrm{IV})$ oxidative quenching pathway.

Initially, we examined the rate at which the DCB radical anion can undergo back electron transfer (BET) with the $\operatorname{Ir}(\mathrm{IV})$ species to regenerate the ground state transition metal complex. In order to identify spectroscopic features of $\left[\operatorname{Ir}(\mathrm{ppy})_{3}\right]^{+}$and $\mathrm{DCB}^{--}$, we utilized spectroelectrochemistry. Upon oxidation of $\operatorname{Ir}(\mathrm{ppy})_{3}$, positive absorption features appear at wavelengths shorter than $346 \mathrm{~nm}$ and longer than $478 \mathrm{~nm}$, with a decrease in absorbance between those wavelengths (Figure S1). At wavelengths shorter than $450 \mathrm{~nm}$, there are several large, positive absorption features, which differ from the featureless ground state of DCB (Figure S3) ${ }^{50}$ 


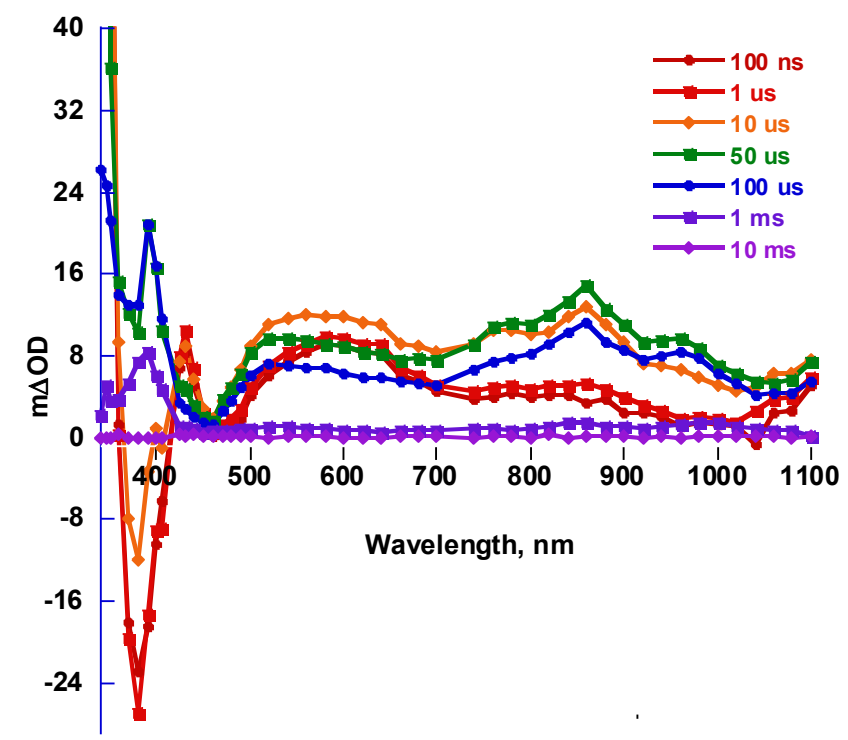

Figure 2. Transient absorption spectrum of $37 \mu \mathrm{M} \operatorname{Ir}(\text { ppy })_{3}$ and $50 \mathrm{mM}$ DCB at $415 \mathrm{~nm}$ excitation from $100 \mathrm{~ns}$ to $10 \mathrm{~ms}$.

We collected TAS data from 100 ns to 10 $\mathrm{ms}$ and from 340 to $1100 \mathrm{~nm}$ (Figure 2). Initially in the TAS spectrum there are positive absorption features at wavelengths longer than $460 \mathrm{~nm}$ and a bleach centered at $380 \mathrm{~nm}$. Both are consistent with the formation of $\operatorname{Ir}(\mathrm{IV})$. There is also a new absorption at $\sim 430 \mathrm{~nm}$ that we assign to the DCB radical anion. At $100 \mathrm{~ns}$, the transient spectrum could be reproduced by combining the difference spectra obtained from the spectroelectrochemical spectrum for $\left[\operatorname{Ir}(\mathrm{ppy})_{3}\right]^{+}$and $\mathrm{DCB}^{-}$. From this, we determine an initial concentration of $3.55 \mu \mathrm{M}$ for both species (Figure 3).

Unexpectedly, at longer times $(>1 \mu \mathrm{s})$ we see changes in the transient spectra that are con-

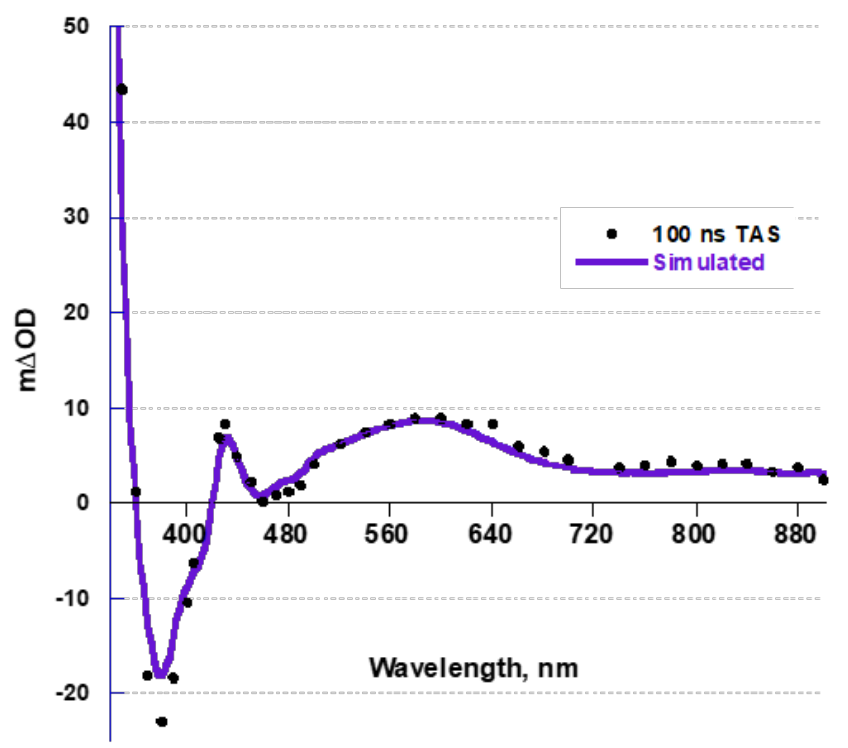

Figure 3. TAS spectrum at $100 \mathrm{~ns}$ of $\operatorname{Ir}(\mathrm{ppy})_{3}$ and DCB excited at $415 \mathrm{~nm}$ with simulated changes in absorption based on spectroelectrochemical analysis using a concentration of $3.55 \mu \mathrm{M}$ for $\operatorname{Ir}(\mathrm{IV})$ and $\mathrm{DCB}^{-}$.

sistent with the formation of a new species. Most notably, a new absorption at $\sim 850 \mathrm{~nm}$ forms on a tens of millisecond timescale that cannot be assigned to either $\left[\operatorname{Ir}(\mathrm{ppy})_{3}\right]^{+}$or $\mathrm{DCB}^{--}$. In addition, the bleach at $380 \mathrm{~nm}$ is replaced by a new absorption, and the absorption at $600 \mathrm{~nm}$ blueshifts and changes shape. Kinetic modeling using our measured value of $\mathrm{k}_{\text {quench }}$ demonstrates that oxidation of excited $\operatorname{Ir}(\mathrm{ppy})_{3}$ by DCB is complete within $70 \mathrm{~ns}$ and thus can be excluded on a microsecond timescale. Instead, we suggest the new species is a result of solvent oxidation by $\operatorname{Ir}(\mathrm{IV})$ to form the dimethylacetamide radical cation, $\mathrm{DMA}^{*+}$. Radical cations of N,N-dimethyl amides exhibit absorption bands in the near-UV $(\sim 360-$ $380 \mathrm{~nm})$ as well as absorption features in the
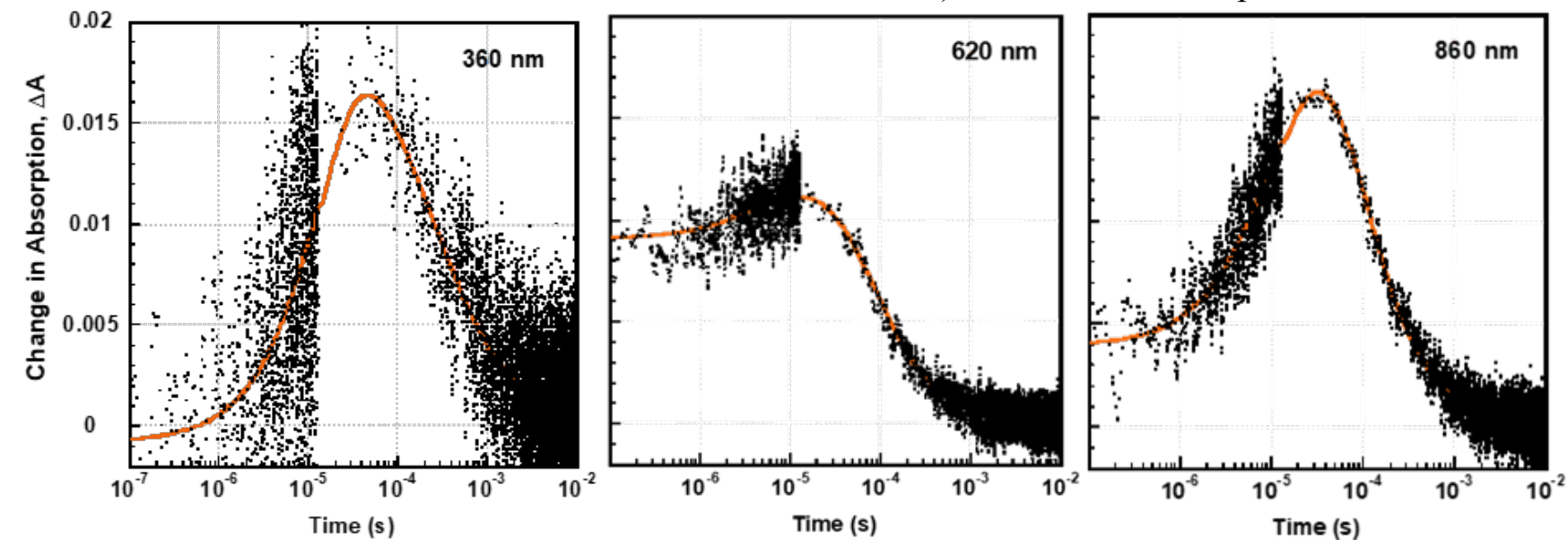

Figure 4. Single wavelength traces of $3.7 \mu \mathrm{MIr}(\mathrm{ppy}) 3,50 \mathrm{mM} \mathrm{DCB}$ at $360 \mathrm{~nm}, 620 \mathrm{~nm}$, and $860 \mathrm{~nm}$ at $415 \mathrm{~nm}$ excitation $\left(0.9 \mathrm{~mJ} / \mathrm{cm}^{2}\right.$ per pulse, gray). Orange line is fit to kinetic model. 
near-IR, ${ }^{51,52}$ which is consistent with our observations.

In order to understand the kinetics of electron transfer between $\operatorname{Ir}(\mathrm{ppy})_{3}$, DCB, and DMA we developed a kinetic model that incorporates BET between $\operatorname{Ir}(\mathrm{IV})$ and $\mathrm{DCB}^{--}\left(\mathrm{k}_{\text {recomb }}\right)$, oxidation of DMA by $\operatorname{Ir}(\mathrm{IV})\left(\mathrm{k}_{\text {scav }}\right)$, and electron transfer between $\mathrm{DMA}^{\circ+}$ and $\mathrm{DCB}^{--}\left(\mathrm{k}_{\mathrm{recomb} 2}\right)$ and applied it to the single wavelength absorption traces (Figure 4). From the fit of ten different wavelengths, we calculated an average rate constant for recombination, $\mathrm{k}_{\text {recomb }}$, of $1.1( \pm 0.4) \times 10^{10}$ $\mathrm{M}^{-1} \mathrm{~s}^{-1}$. Though this recombination is nearly diffusion controlled, the low concentration of $\operatorname{Ir}(\mathrm{IV})$ and $\mathrm{DCB}^{--}$mean it is not the dominant pathway. Instead, the model suggests that $\operatorname{Ir}(\mathrm{IV})$ oxidizes the solvent to form $\mathrm{DMA}^{\cdot+}$. Even though $\mathrm{k}_{\text {scav }}$ is relatively small, $6.3( \pm 0.8) \times 10^{5} \mathrm{M}^{-1} \mathrm{~s}^{-1}$, the high concentration of the solvent means that most of the $\operatorname{Ir}(\mathrm{IV})$ is reduced back to $\operatorname{Ir}(\mathrm{III})$ by generating $\mathrm{DMA}^{*+}$. Subsequent electron transfer between $\mathrm{DMA}^{\circ+}$ and $\mathrm{DCB}^{--}$resets the system in the absence of NPP. The kinetic model predicts that this process is also diffusion controlled $\left(\mathrm{k}_{\text {recomb2 }}=\right.$ $\left.1.5( \pm 0.3) \times 10^{10} \mathrm{M}^{-1} \mathrm{~s}^{-1}\right)$ but the electron transfer takes place over microseconds because of the low concentrations of $\mathrm{DMA}^{\circ+}$ and $\mathrm{DCB}^{\circ-}$.

Electron transfer between DCB, NPP, and $\operatorname{Ir}(\mathbf{p p y})_{3}$. Following our TAS studies with only DCB and $\operatorname{Ir}(\text { ppy })_{3}$, we then included NPP. It is immediately obvious that the transient spectra are remarkably different with NPP added (Figure 5). On short timescales $(<10 \mu \mathrm{s})$ there is a broad absorbance from 400-600 nm with a sharp peak at $440 \mathrm{~nm}$. There is also a slight increase in absorption in the near-IR. We assign the broad 400-600 $\mathrm{nm}$ absorption to the formation of $\mathrm{NPP}^{\circ+}$ and the peak at $440 \mathrm{~nm}$ to $\mathrm{DCB}^{--} .^{53} \mathrm{We}$ do not see any features that we can assign to $\left[\operatorname{Ir}(\mathrm{ppy})_{3}\right]^{+}$, which suggests that oxidation of NPP is complete within 100 ns. While this precludes us from making a definitive assignment for the rate constant of oxidation, $\mathrm{k}_{\mathrm{ox}}$, we can use kinetic modeling to estimate a minimum value of $\mathrm{k}_{\mathrm{ox}}$ as $4 \times 10^{8} \mathrm{M}^{-1} \mathrm{~s}^{-1}$, assuming an initial concentration of $3.55 \mu \mathrm{M}$ of excited $\operatorname{Ir}(\text { ppy })_{3}$.

At $10 \mu$ s and longer, the transient spectra change dramatically. Most notably a large transient absorption develops in the near IR from 700 to $1100 \mathrm{~nm}$ as well as an increase in the absorption between 400 and $600 \mathrm{~nm}$. While to the best of our knowledge the absorption spectrum for NPP $^{*}$ is not available, these absorption features are generally consistent with alkane radicals. ${ }^{54,55}$

Single wavelengths traces (Figure 6) confirm the formation of a new species on a 10-100 $\mu$ s timescale, followed by decay over milliseconds. We could not fit these traces using a simple exponential model and so we expanded the kinetic model used in the $\operatorname{Ir}(\mathrm{ppy})_{3} / \mathrm{DCB}$ experiments to include deprotonation of $\mathrm{NPP}^{\cdot+}, \mathrm{k}_{\text {deprot }}$, and coupling of $\mathrm{NPP}^{\bullet}$ and $\mathrm{DCB}^{\circ}, \mathrm{k}_{\text {couple. }}$. We also found that the data could not be fit unless we also included a term that described electron transfer between $\mathrm{DCB}^{--}$and $\mathrm{NPP}^{\circ+}, \mathrm{k}_{\mathrm{rad}}$ recomb, which results in the regeneration of DCB and NPP. Using our expanded model, we were able to fit the TAS traces and extract the relevant rate constants. We obtain a value of $1.0( \pm 0.1) \times 10^{10} \mathrm{M}^{-1} \mathrm{~s}^{-1}$ for $\mathrm{k}_{\mathrm{cou}-}$ ple, $3.0( \pm 0.1) \times 10^{10} \mathrm{M}^{-1} \mathrm{~s}^{-1}$ for $\mathrm{k}_{\mathrm{rad}}$ recomb, and $7( \pm 1) \times 10^{5} \mathrm{M}^{-1} \mathrm{~s}^{-1}$ for $\mathrm{k}_{\text {deprot. }}$

It is important to note that we did not include sodium acetate in our TAS experiments because we suggest that it is not the primary proton acceptor from $\mathrm{NPP}^{*+}$. For one, sodium acetate is completely insoluble in DMA, which would make rapid deprotonation of $\mathrm{NPP}^{\circ+}$ less likely. Also, we measured the apparent deprotonation rate of NPP•+ electrochemically and observed no

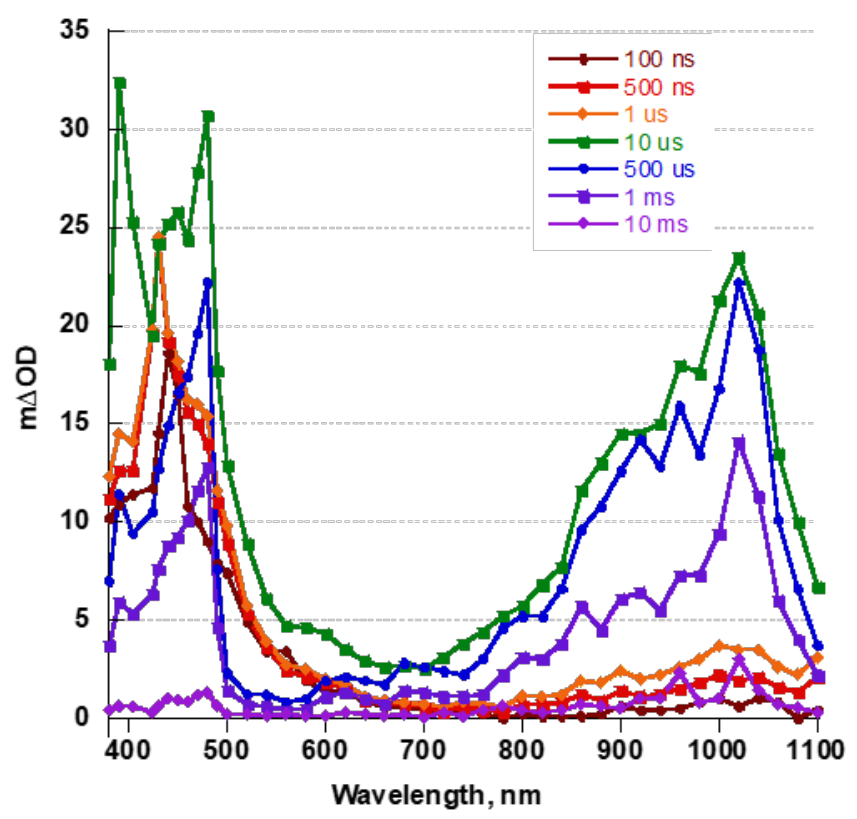

Figure 5. Transient Absorption Spectrum of $37 \mu \mathrm{M} \operatorname{Ir}(\mathrm{ppy})_{3}$, $50 \mathrm{mM} \mathrm{DCB}$, and $150 \mathrm{mM} \mathrm{NPP}$ at $415 \mathrm{~nm}$ excitation from $100 \mathrm{~ns}$ to $10 \mathrm{~ms}$. 

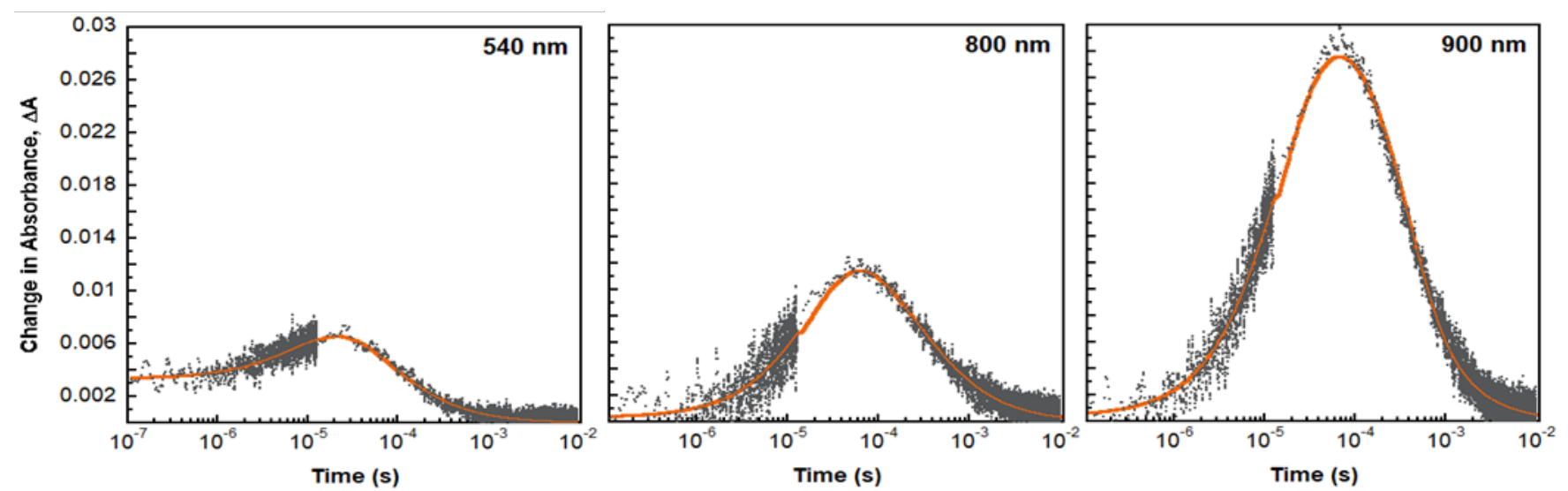

Figure 6. Single wavelength traces of $3.7 \mu \mathrm{M} \operatorname{Ir}(\mathrm{ppy}) 3,50 \mathrm{mM}$ DCB, and $150 \mathrm{mM}$ NPP at $540 \mathrm{~nm}, 800 \mathrm{~nm}$, and $900 \mathrm{~nm}$ at $415 \mathrm{~nm}$ excitation $\left(0.9 \mathrm{~mJ} / \mathrm{cm}^{2}\right.$ per pulse, gray). Orange line is fit to kinetic model.

difference in the rate with or without sodium acetate (Figure S12). Lastly, Walker et al. observed that removal of sodium acetate from the coupling of 1,4-DCB and piperidines had no effect on the reaction. ${ }^{44}$ Instead, we suggest that NPP functions as the primary proton acceptor in the reaction as it is present as a higher concentration than sodium acetate and completely soluble in DMA. The slow deprotonation step is likely related to NPP being a weak base (reported pKa between 3.24 and 5.68). ${ }^{56,57}$ Over time we do observe the formation of acetic acid, which suggests that the protonated NPP can subsequently transfer a proton to the sodium acetate.

Kinetic Model. Our TAS data indicates that most of the reaction steps in the coupling of DCB and NPP occur at or near diffusion control, which is consistent with radical reactions. ${ }^{58}$ Interestingly, we can see from Figure 7 that the unproductive pathways (red) typically have larger rate constants than the productive pathways (black). Product is produced, however, because in most cases the unproductive steps require two low concentration species (e.g., back electron transfer between $\left[\operatorname{Ir}(\mathrm{ppy})_{3}\right]^{+}$and $\left.\mathrm{DCB}^{--}\right)$, while the productive steps typically exploit one reagent at a high concentration (e.g., oxidation of NPP by $\left.\left[\operatorname{Ir}(\text { ppy })_{3}\right]^{+}\right)$.

Our results also allow us to explain why the quantum yield of the reaction is less than 1 . Because the oxidized $\operatorname{Ir}(\mathrm{ppy})_{3}$ is rapidly reduced back to Ir(III) by NPP and no longer plays a role in the reaction, the only obvious way for the reaction to exhibit a quantum yield less than 1 is either through significant coupling of NPP ${ }^{\circ}$ to form dimers or electron transfer between $\mathrm{DCB}^{--}$and $\mathrm{NPP}^{\circ+}$. Within our NMR studies, we have not observed significant NPP dimerization or other product formation, which supports electron transfer between the two radical ions controlling the outcome of the reaction. This also explains why deprotonation of $\mathrm{NPP}^{\cdot+}$ is the rate-limiting step in the reaction (Figure 7); the slower the deprotonation, the more time for $\mathrm{DCB}^{--}$and $\mathrm{NPP}^{\circ+}$ to undergo recombination.

We also investigated whether we could use the simple kinetic model used to fit the TAS data to also make predictions about the reaction. Using the rate constants we obtained from TAS experiments and assuming an initial pulse of light generates a concentration of $3.55 \mu \mathrm{M}$ excited $\operatorname{Ir}(\text { ppy })_{3}$, the kinetic model predicts a quantum yield of 0.584 . Our steady state QY measurements observed QYs in the range of $0.15-0.3$, so this value is in good agreement. It is important to note that the value of $0.2-0.3$ is an external quantum yield, i.e., it is based on the number of incident photons. While at $415 \mathrm{~nm}$ nearly all those photons should be absorbed, the presence of the insoluble sodium acetate leads to scattering and a lower external QY. Additionally, our simple kinetic model does not account for off-cycle pathways such as dimerization of NPP ${ }^{\cdot}$ or proton transfer between sodium acetate and protonated NPP, which may or may not occur. For example, Figure S5 demonstrates that inclusion of dimerization of NPP' into the model could certainly shift the QY into the range of our observed numbers.

As expected, the quantum yield of the reaction is highly dependent on the rate of deproto- 


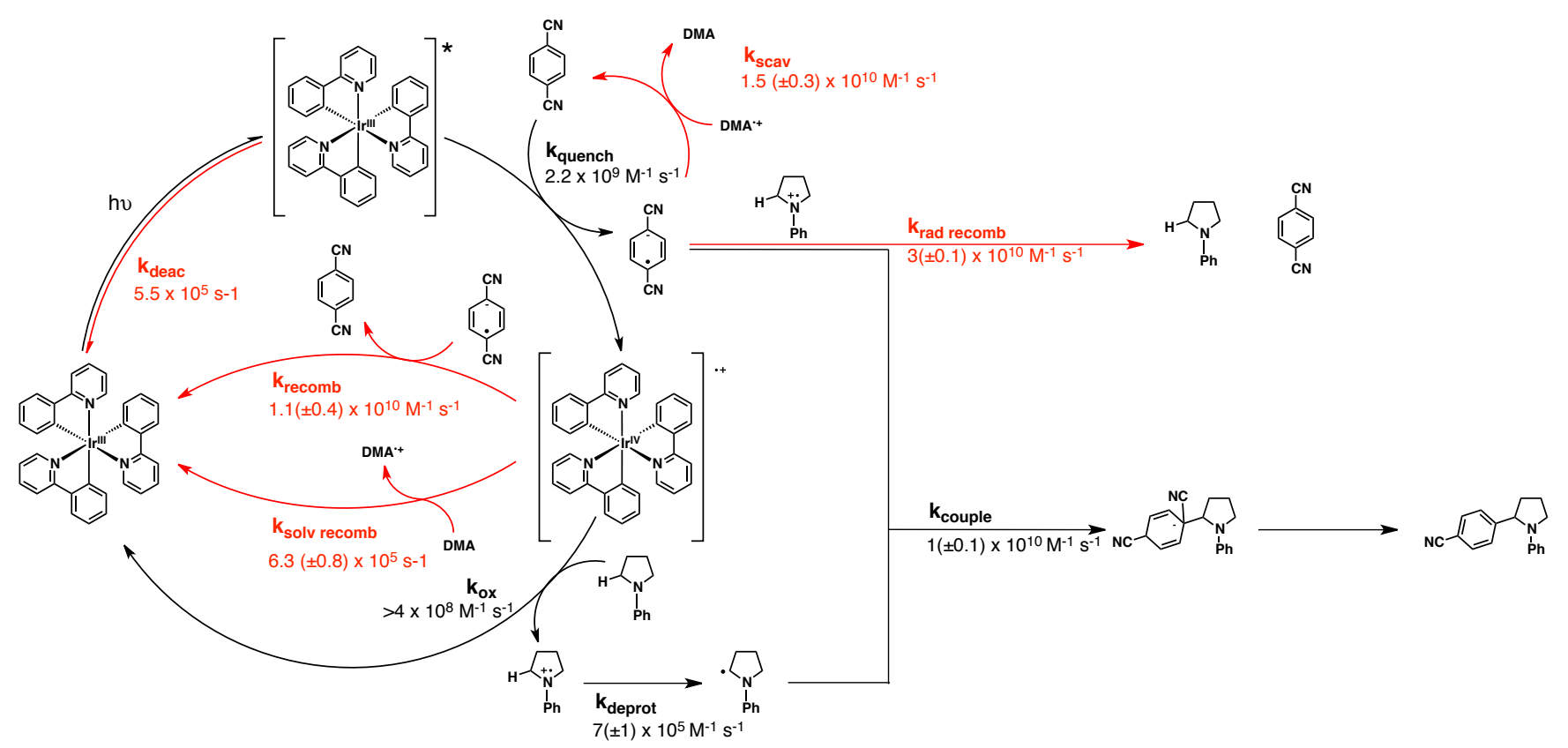

Figure 7. Overall kinetic scheme with rate constants for the coupling of N-phenylpyrrolidine (NPP) and 1,4-dicyanobenzene (DCB). Red arrows indicate steps that are catalytically unproductive.

nation. The model suggests that if the rate deprotonation step were increased by just one order of magnitude then the reaction would give quantum yields near 1 (Figure S6). By contrast, slowing the rate by an order of magnitude would decrease the quantum yield by nearly two thirds. This predicts that adding a better proton acceptor than NPP should result in a higher quantum yield. The model suggests that if the radical recombination step was slower by two magnitudes, the reaction quantum yield could be near 1 (Figure S7).

Interestingly, there is a significant amount of kinetic redundancy in this reaction. For example, slowing the rate of quenching of excited $\operatorname{Ir}(\text { ppy })_{3}$ by more than order of magnitude is predicted to have little impact on the reaction. (Figure S8). Likewise, the oxidation of NPP by Ir(IV) or rate of coupling between $\mathrm{NPP}^{\circ}$ and $\mathrm{DCB}^{\circ}$ could be slowed by several orders of magnitude without impacting the reaction (Figures S9 and S10).

The peak in the QY data (Figure 1) is likely related formation of acetic acid. As sodium acetate is protonated to form acetic acid, the size of the insoluble particles will decrease along with the scattering efficiency. We have observed that reactions that do not pre-grind the sodium acetate result in lower QY. As fewer photons are scattered, the external QY should increase closer to the value predicted by the kinetic modeling, ex- plaining the increase in QY over the first five hours of the reaction. At the same time, we suggest that acetic acid can be oxidized instead of NPP. Oxidative decarboxylation is well known in photoredox catalysis, ${ }^{59,60}$ suggesting it is plausible that acetic acid can function as an electron donor to $\left[\operatorname{Ir}(\mathrm{ppy})_{3}\right]^{+}$. Fragmentation to form a methyl radical is unlikely, suggesting that electron transfer with $\mathrm{DCB}^{--}$to regenerate acetic acid and DCB may occur. The increase in acetic acid over time would explain the decrease in QY we observe over time.

Using our modeling, we can also consider the QY results reported by Walker et al. ${ }^{44}$ for the coupling of piperidine with DCB and this report (0.4-0.6 vs. $0.15-0.3)$. In that study, the authors report that oxidation of the piperidine, $\mathrm{k}_{\mathrm{ox}}$, is at least one magnitude slower $\left(2.4 \times 10^{7} \mathrm{M}^{-1} \mathrm{~s}^{1}\right)$ than what we observe $\left(>4 \times 10^{8} \mathrm{M}^{-1} \mathrm{~s}^{-1}\right)$. This difference in rate is likely related to the presence of a methyl group adjacent to the amine nitrogen. By extension, we also propose that recombination between the piperidine radical cation and $\mathrm{DCB}^{-}$ is also slowed by the same methyl group. Our kinetic modeling suggests that $\mathrm{k}_{\mathrm{ox}}$ can be as slow as $10^{6} \mathrm{M}^{-1} \mathrm{~s}^{-1}$ without having a significant impact on the overall QY. The higher QY in that study may then be related to the lack of scattering from sodium acetate or slowing of electron transfer between the radical cation and $\mathrm{DCB}^{\circ}$. This elec- 
tron transfer step $\left(\mathrm{k}_{\mathrm{rad}}\right.$ recomb $)$ is predicted to to have a profound effect on the QY of the reaction and may be slowed by the methyl group.

\section{CONCLUSION.}

Through a combination of steady state photochemical measurements, laser spectroscopy, and electrochemical methods we have rigorously characterized a photoredox reaction that is broadly relevant to wide range of transformations. While the overall yield of the reaction is high ( $86 \%$ in our hands) the external QY of the reaction is more modest, only 0.15 to 0.3 depending on the length of the reaction. We also find that when normalizing for the number of photons, there is no difference in the reaction rate between high and low illumination intensities.

Using transient laser spectroscopy and kinetic modeling, we have determined the rate constants for the main productive and nonproductive pathways in a model $\alpha$-aminoarylation cross-coupling reaction between DCB and NPP. Our studies reveal that deprotonation of the NPP radical cation is the rate-limiting step. This step acts as gatekeeper to coupling of the radicals and limits the reaction by enabling electron transfer to occur between the two radical anions, which essentially resets the reaction.

Finally, we developed a simple kinetic model and using the rate constants we obtained, predicted a QY of 0.58 , which is in good agreement with our experimentally measured QY. We were then able to use that model to predict the effect of changing various kinetic parameters. As expected, changing the rate of deprotonation or electron transfer between the radical ions is predicted to significantly impact the QY of the reaction. There is also significant kinetic redundancy in the reaction as the quenching, oxidation, and coupling rates can all be slowed several orders of magnitude without appreciable effects.

\section{ASSOCIATED CONTENT}

\section{Supporting Information}

The Supporting Information is available free of charge on the ACS Publications website.

Kinetic model equations, QY data figures, Spectroelectrochemical $\Delta \varepsilon$ spectra, Simulated rate constant data from kinetic modeling. Electrochemical data for the rate of deprotonation. (PDF)

\section{AUTHOR INFORMATION}

\section{Corresponding Author}

*E-mail: jswierk@binghamton.edu

\section{ACKNOWLEDGMENT}

The authors thank Binghamton University for start-up funding. EHS and BGS thank the Chemistry department for summer fellowships. We thank Profs. Jennifer Hirschi and Matthew Vetticatt (Binghamton University) for helpful advice on quantitative NMR measurements and discussions on the reaction mecahism.

\section{REFERENCES}

1. Nicewicz, D. A. and MacMillan, D. W. C. Merging Photoredox Catalysis with Organocatalysis: The Direct Asymmetric Alkylation of Aldehydes. Science. 2008, 322, 77-80.

2. Ischay, M. A.; Anzovino, M. E.; Du, J.; Yoon, T. P. Efficient Visible Light Photocatalysis of [2+2] Enone Cycloadditions. J. Am. Chem. Soc. 2008, 130, 12886-12887.

3. Narayanam, J.M.R.; Stephenson, C.R.J. Visible Light Photoredox Catalysis: Applications in Organic Synthesis. Chem. Soc. Rev. 2011, 40, 102-113.

4. Prier, C. K.; Rankic, D. A.; MacMillan, D. W. C. Visible Light Photoredox Catalysis with Transition Metal Complexes: Applications in Organic Synthesis. Chem. Rev. 2013, 113, 5322-5363.

5. Romero, N. A.; Nicewicz, D. A. Organic Photoredox Catalysis. Chem. Rev. 2016, 116, 10075-10166.

6. Yoon, T. Photochemical Stereocontrol Using Tandem PhotoredoxChiral Lewis Acid Catalysis. Acc. Chem. Res. 2016, 49, 2307-2315.

7. Matsui, J. K.; Lang, S. B.; Heitz, D. R.; Molander, G. A. Photoredox-Mediated Routes to Radicals: the Value of Catalytic Radical Generation in Synthetic Methods Development. ACS Catalysis 2017, 7, 2563-2575.

8. Arias-Rotonda, D. M.; McCusker, J. K. The Photophysics of Photoredox Catalysis: A Roadmap for Catalyst Design. Chem. Sci. Rev. 2016, 45, 5803-5820.

9. Pitre, S.P.; McTiernan, C.D.; Scaiano, J.C. Understanding the Kinetics and Spectroscopy of Photoredox Catalysis and TransitionMetal-Free Alternatives. Acc. Chem. Res. 2016, 49, 1320-1330.

10. Blanksby, S. J.; Ellison, G. B. Bond Dissociation Energies of Organic Molecules. Acc. Chem. Res. 2003, 36, 255-263.

11. Waidmann, C. R.; Miller, A. J. M.; Ng, C.-W. A.; Scheuermann, M. L.; Porter, T. R.; Tronic, T. A.; Mayer, J. M. Using Combinations of Oxidants and Bases as PCET Reactants: Thermochemical and Practical Considerations. Energy Environ. Sci. 2012, 5, 7771-7780.

12. Ruccolo, S.; Qin, Y.; Schnedermann, C.; Nocera, D. G. General Strategy for Improving the Quantum Efficiency of Photoredox Hydroamidation Catalysis. J. Am. Chem. Soc. 2018, 140, 14926-14937.

13. Thompson, W. A.; Fernandez, E. S.; Maroto-Valer, M. M. Review and Analysis of $\mathrm{CO}_{2}$ Photoreduction Kinetics. ACS Sustainable Chem. Eng. 2020, 8, 4677-4692.

14. Ravelli, D.; Fagnoni, M. Dyes as Visible Light Photoredox Organocatalysts. Chem CatChem 2012, 4, 169-171.

15. Larsen, C.B.; Wenger, O.S. Photoredox Catalysis with Metal Complexes Made from Earth-Abundant Elements. Chem. Eur. J. 2018, 24, 2039-2058.

16. Teegardin, K.; Day, J. I.; Chan, J.; Weaver, J. Advances in Photocatalysis: A Microreview of Visible Light Mediated Ruthenium and Iridium Catalyzed Organic Transformations. Org. Process. Res. Dev. 2016, 20, 1156-1163.

17. Yoon, T. P. Visible Light Photocatalysis: The Development of Photocatalytic Radical Ion Cycloadditions. ACS Catal. 2013, 3, 895902 .

18. Koyama, D.; Dale, D.J.A.; Orr-Ewing, A.J. Ultrafast Observation of a Photoredox Reaction Mechanism: Photoinitiation in Organocata- 
lyzed Atom-Transfer Radical Polymerization. J. Am. Chem. Soc. 2018, 140, 1285-1293.

19. Lewis-Borell, L.; Sneha, M.; Bhattacherjee, A.; Clark, I. P.; OrrEwing, A. J. Mapping the Multi-step Mechanism of a Photoredox Catalyzed Atom-Transfer Radical Polymerization Reaction by Direct Observation of the Reactive Intermediates. Chem. Sci. 2020, 11, 4475-4481.

20. Herzog, W.; Bronner, C.; Löffler, S.; He, B.; Kratzert, D.; Stalke, D.; Hauser, A.; Wenger, O.S. Electron Transfer between HydrogenBonded Pyridylphenols and a Photoexcited Rhenium(I) Complex. ChemPhysChem 2013, 14, 1168-1176.

21. Rueda-Becerril, M.; Mahé, O.; Drouin, M.; Majewski, M.B.; West, J.G.; Wolf, M.O.; Sammis, G.M.; Paquin, J-F. Direct C-F Bond Formation Using Photoredox Catalysis. J. Am. Chem. Soc. 2014, 136, 2637-2641.

22. Majek, M.; Jacobi von Wangelin, A. Mechanistic Perspectives on Organic Photoredox Catalysis for Aromatic Substitutions. Acc. Chem. Res. 2016, 49, 2316-2327.

23. Ng, Y.Y.; Tan, L.J.; Ng, S.M.; Chai, Y.T.; Ganguly, R.; Du, Y.; Yeow, E.K.L.; Soo, H.S. Spectroscopic Characterization and Mechanistic Studies on Visible Light Photoredox Carbon-Carbon Bond Formation by Bis(Arylimino)Acenaphthene Copper Photosensitizers. ACS Catal. 2018, 8(12), 11277-11286.

24. Ma, J.; Zhang, X.; Phillips, D.L. Time-Resolved Spectroscopic Observation and Characterization of Water-Assisted Photoredox Reactions of Selected Aromatic Carbonyl Compounds. Acc. Chem. Res. 2019, 52, 726-737.

25. Ting, S.I.; Garakyaraghi, S.; Taliaferro, C.M.; Shields, B.J.; Scholes, G.D.; Castellano, F.N.; Doyle, A.G. ${ }^{3}$ d-d Excited States of Ni(II) Complexes Relevant to Photoredox Catalysis: Spectroscopic Identification and Mechanistic Implications. J. Am. Chem. Soc. 2020, 142, 5800-5810.

26. Zheng, S.; Zhang, S-Q.; Saeednia, B.; Zhou, J.; Anna, J.M.; Hong, X.; Molander, G.A. Diastereoselective Olefin Amidoacylation via Photoredox PCET/Nickel-Dual Catalysis: Reaction Scope and Mechanistic Insights. Chem. Sci. 2020, 11, 4131-4137.

27. Coles, M.S.; Quach, G.; Beves, J.E.; Moore, E.G. A Photophysical Study of the Sensitization-Initiated Electron Transfer: Insights into the Mechanism of Photoredox Activity. Angew. Chem. Int. Ed. 2020, 59(24), 9522-9526.

28. Wang, K.; Lu, H.; Zhu, X.; Lin, Y.; Beard, M.C.; Yan, Y.; Chen, $\mathrm{X}$. Ultrafast Reaction Mechanisms in Perovskite Based Photocatalytic C-C Coupling. ACS Energy Lett. 2020, 5, 566-571.

29. Vitaku, E.; Smith, D.T.; Njardarson, J.T. Analysis of the Structural Diversity, Substitution Patterns, and Frequency of Nitrogen Heterocycles among U.S. FDA Approved Pharmaceuticals. J. Med. Chem. 2014, 57, 10257-10274.

30. Chen, W.; Ma, L.; Paul, A.; Seidel, D. Direct $\alpha-\mathrm{C}-\mathrm{H}$ Bond Functionalization of Unprotected Cyclic Amines. Nature Chem. 2018, 10, 165-169.

31. Spangler, J.E.; Kobayashi, Y.; Verma, P.; Wang, D-H.; Yu, J-Q. $\alpha$-Arylation of Saturated Azacycles and $N$-Methylamines via Palladium(II)-Catalyzed C( $\left.\mathrm{sp}^{3}\right)$-H Coupling. J. Am. Chem. Soc. 2015, 137, 11876-11879.

32. Shaw, M.H.; Shurtleff, V.W.; Terrett, J.A.; Cuthbertson, J.D.; MacMillan, D.W.C. Native Functionality in Triple Catalytic CrossCoupling: $\mathrm{sp}^{3} \mathrm{C}-\mathrm{H}$ Bonds as Latent Nucleophiles. Science 2016, 352, 1304-1308.

33. McNally, A.; Prier, C. K.; MacMillan, D. W. C. Discovery of an $\alpha$-Amino C-H Arylation Reaction Using the Strategy of Accelerated Serendipity. Science 2011, 334 (6059), 1114-1117.

34. Pirnot, M.T.; Rankic, D.A.; Martin, D.B.C.; MacMillan, D.W.C. Photoredox Activation for the Direct $\beta$-Arylation of Ketones and Aldehydes. Science 2013, 339, 1593-1596.

35. Noble, A.; MacMillan, D.W.C. Photoredox $\alpha$-Vinylation of $\alpha$ Amino Acids and N-Aryl Amines. J. Am. Chem. Soc. 2014, 136, 11602-11605.
36. Qvortrup, K.; Rankic, D.A.; MacMillan, D.W.C. A General Strategy for Organocatalytic Activation of $\mathrm{C}-\mathrm{H}$ Bonds via Photoredox Catalysis: Direct Arylation of Benzylic Ethers. J. Am. Chem. Soc. 2014, 136, 626-629.

37. Zuo, Z.; Ahneman, D.T.; Chu, L.; Terret, J.A.; Doyle, A.G.; MacMillan, D.W.C. Merging Photoredox with Nickel Catalysis: Coupling of $\alpha$-carboxyl $\mathrm{sp}^{3}$-carbons with Aryl Halides. Science 2014, 345 , 437-440.

38. Jin, J.; MacMillan, D.W.C. Direct $\alpha$-Arylation of Ethers through the Combination of Photoredox-Mediated C-H Functionalization and Minisci Reaction. Angew. Chem. Int. Ed. 2015, 54, 1565-1569.

39. Ahneman, D.T.; Doyle, A.G. C-H Functionalization of Amines with Aryl Halides by Nickel-Photoredox Catalysis. Chem. Sci. 2016, 7, 7002-7006.

40. Heitz, D.R.; Tellis, J.C.; Molander, G.A. Photochemical NickelCatalyzed C-H Arylation: Synthetic Scope and Mechanistic Investigations. J. Am. Chem. Soc. 2016, 138, 12715-12718.

41. Ide, T.; Barham, J.P.; Fujita, M.; Kawato, Y.; Egami, H.; Hamashima, Y. Regio- and Chemoselective $\mathrm{Csp}^{3}-\mathrm{H}$ Arylation of Benzylamines by Single Electron Transfer/Hydrogen Atom Transfer Synergistic Catalysis. Chem. Sci. 2018, 9, 8453-8460.

42. Revathi, L.; Ravindar, L.; Fang, W-Y.; Rakesh, K.P.; Qin, H-L. Visible Light-Induced $\mathrm{C}-\mathrm{H}$ Bond Functionalization: A Critical Review. Adv. Synth. Catal. 2018, 360, 4652-4698.

43. Ma, Y.; Yao, X.; Zhang, L.; Ni, P.; Cheng, R.; Ye, J. Direct Arylation of $\alpha$-Amino $\mathrm{C}\left(\mathrm{sp}^{3}\right)$-H Bonds by Convergent Paired Electrolysis. Angew. Chem. Int. Ed. 2019, 58, 16548-16552.

44. Walker, M. M.; Koronkiewicz, B.; Chen, S.; Houk, K. N.; Mayer, J.; Ellman, J. A. Highly Diastereoselective Functionalization of Piperidines by Photoredox-Catalyzed $\alpha$-Amino C-H Arylation and Epimerization. J. Am. Chem. Soc. 2020, 142, 8194-8202.

45. Rimshaw, A.; Grieco, C.; Asbury, J.B. Note: Using Fast Digitizer Acquisition and Flexible Resolution to Enhance Noise Cancellation for High Performance Nanosecond Transient Absorbance Spectroscopy. Rev. Sci. Instrum. 2015, 86, 066107-1-066107-3.

46. Dethe, D. H.; Srivastava, A.; Dherange, B. D.; Kumar, B. V. Unsymmetrical Disulfide Synthesis through Photoredox Catalysis. Adv. Synth. Catal. 2018, 360, 3020-3025.

47. Xu, W.; Wang, W.; Liu, T.; Xie, J.; Zhu, C. Late-stage trifluoromethylthiolation of benzylic C-H bonds. Nature Comm. 2019, 10, 1-8. 48. Lei, Z.; Banerjee, A.; Kusevska, E.; Rizzo, E.; Liu, P.; Ngai, M$\mathrm{Y} ; \beta$-Selective Aroylation of Activated Alkenes by Photoredox Catalysis. Angew. Chem. Int. Ed. 2019, 58(22), 7318-7323.

49. Hofbeck, T.; Yersin, H. The Triplet State of Fac-Ir(ppy) $)_{3}$ Inorg. Chem. 2010, 49, 9290-9299.

50. Nakashima, H.; Shida, T. Nakatsuji, H. Electronic Excitation Spectra of Radical Anions of Cyanoethylenes and Cyanobenzenes: Symmetry Adapted Cluster- Configuration Interaction study. $J$. Chem. Phys. 2011, 136, 214306-1-214306-13.

51. Nuzhdin, K.B.; Feldman, V.I. Structure and Photochemistry of "Bridged" Bifunctional Radical Cations: Amidoesters vs. Amides. Rad. Phys. Chem. 2008, 77, 416-427.

52. Mel'nikov, M.Y.; Belevskii, V.N.; Belopushkin, S.I.; Mel'nikova, O.L. Photochemical Reactions of Radical Cations of Dimethylformamide in Freon Matrices at 77 K. Rus. Chem. Bull. 1997, 46, 12451247.

53. Sumalekshmy, S.; Gopidas, K.R. Reaction of Aromatic Amines with $\mathrm{Cu}\left(\mathrm{ClO}_{4}\right)_{2}$ in acetonitrile as a Facile Route to Amine Radical Cation Generation. Chem. Phys. Lett. 2005, 413, 294-299.

54. van den Bosch, A.; Stienlet, D.; Ceulemans, J. Spectroscopic Characterization of Alkane Radical Cations - I. Electron Absorption Spectra of 3-Methylalkane Radical Cations. Radiat. Phys. Chem. 1989, 33, 371-379.

55. Ichikawa, T.; Ota, N. ESR and Electronic Spectra of Alkane Radical Cations Formed in $\gamma$-Irradiated 3-Methylpentane and 3Methylhexane Glasses Containing Alkane Solutes. J. Phys. Chem. 1987, 91, 3244-3248. 
56. SciFinder; Chemical Abstracts Service: Columbus, OH; Chemical; pKa; https://scifinder.cas.org (accessed June 4, 2020); calculated using ACD/Labs software, version 11.02; ACD/Labs 1994-2020.

57. Weringa, W.D.; Janssen, M.J. Substituent Effects of Pyrrolidino and Piperidino Groups in Benzoic Acids and Nitrobenzenes. Recueil 1968, 87, 1372-1380.

58. Leifert, D.; Studer, A. The Persistent Radical Effect in Organic Synthesis. Angew. Chem. Int. Ed. 2020, 59 74-108.

59. Miyake, Y.; Nakajima, K.; Nishibayashi, Y. Visible lightmediated oxidative decarboxylation of arylacetic acids into benzyl radicals: addition to electron-deficient alkenes by using photoredox catalysts. Chem. Commun. 2013, 49, 7854-7856.

60. Candish, L.; Freitag, M.; Gensch, T.; Glorius, F. Visible lightmediated oxidative decarboxylation of arylacetic acids into benzyl radicals: addition to electron-deficient alkenes by using photoredox catalysts, Chem. Sci. 2017, 8, 3618-3622. 
(n) 